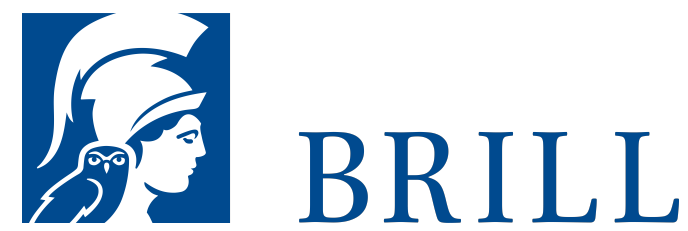

\title{
Staat und Diversität
}

Agonaler Pluralismus für die liberale Demokratie

\section{Author: Frank Schorkopf}

Seit den 1990er-Jahren wird zunehmend hörbar der Anspruch formuliert, dass Diversität gefördert und in den Strukturen von Staat und Gesellschaft verwirklicht werden sollte. Dieser Vielfaltsimperativ überrascht, weil die westliche Gesellschaft mit dem Pluralismus ein tragfähiges Leitbild hat. Diversität steht für ein gesellschaftstheoretisch ambitioniertes Konzept sozialer Ordnung. Der Begriff transportiert - und das macht ihn auch für die Rechtswissenschaft besonders interessant - eine komplexe, überwiegend noch diffuse Demokratietheorie, in dem sich Gesellschafts- und Verfassungstheorie treffen. Die Studie untersucht den tatsächlichen und intellektuellen Rahmen des Diversitätsdenkens, und unternimmt es, die theoretischen und dogmatischen Folgen für den modernen Verfassungsstaat aufzuzeigen. Die These lautet, dass eine diverse Gesellschaft notwendig mit Identitätspolitik einhergeht, in deren Folge identitäre Gruppen nach einem »exklusionsfreien Konsens « verlangen. Diversität und Identität stellen mit ihrer neotribalen Neigung tragende Institutionen des liberalen Verfassungsstaates in Frage, das Mehrheitsprinzip, den Gleichheitssatz und das Politische in der parlamentarischen Demokratie. So belegt die Entpolitisierung gesellschaftlicher Konflikte, dass die Politik gegenüber Diversitätsansprüchen aus der Gesellschaft aufgeschlossen ist, indem sie auf Moral und Recht setzt.... See More

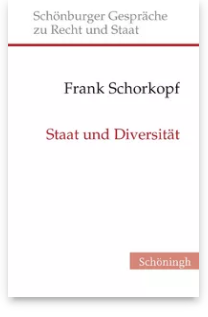

Pages: 104

Seiten

Language:

German

Subjects:

Economics \&

Political Science, Social Sciences

Publisher: Brill |

Schöningh

Series:

Schönburger

Gespräche zu

Recht und Staat,

Volume: 30

E-Book (PDF)

Released online:

19 Oct 2017

ISBN: 978-3-

657-78861-3

List price

Hardback

Publication date: o8 Sep 2017

ISBN: 978-35०6-78861-о

List price 
Frank Schorkopf ist seit 2009 Professor für Öffentliches Recht und Europarecht an der Georg-August-Universität Göttingen.

Frank Schorkopf, geboren 1970. Studium der Rechtswissenschaft an der Universität Hamburg und der London School of Economics. Promotion 1999, nach Aufenthalten als wiss. Mitarbeiter am Max-Planck-Institut für Völkerrecht, beim Bundesverfassungsgericht und an der Universität Bonn, Habilitation 2007. Zum Professor für Öffentliches Recht und Europarecht an die Georg-August-Universität berufen 2009. Ordentliches Mitglied der Akademie der Wissenschaften zu Göttingen seit 2016.

For more information see brill.com

$$
\begin{aligned}
& \text { Order information: Order online at brill.com } \\
& \text { +44 } 33 \circ 333 \text { 0049 | customerservices@brill.com } \\
& \text { Submission information: brill.com/authors }
\end{aligned}
$$

Titles published by Brill | Fink, Brill | mentis or Brill | Schöningh: +49(o)71 5413279216 | brill@brocom.de 